\title{
PGC1 $\alpha$ promotes cisplatin resistance in human ovarian carcinoma cells through upregulation of mitochondrial biogenesis
}

\author{
LUYAN SHEN $^{1}$, BOYANG SUN ${ }^{2}$, JIYAO SHENG $^{3}$, SIHANG YU $^{1}$, \\ YANQING LI ${ }^{1}$, HUADAN XU ${ }^{1}$, JING SU $^{1}$ and LIANKUN SUN ${ }^{1}$ \\ ${ }^{1}$ Department of Pathophysiology, College of Basic Medical Sciences, Jilin University, Changchun, Jilin 130021; \\ ${ }^{2}$ Department of Biochemistry and Molecular Biology, Basic College of Medicine, Yanbian University, \\ Yanbian Korean Autonomous Prefecture, Jilin 133002; ${ }^{3}$ Department of Hepatobiliary and Pancreas Surgery, \\ Second Hospital, Jilin University, Changchun, Jilin 130041, P.R. China
}

Received February 1, 2018; Accepted April 23, 2018

DOI: 10.3892/ijo.2018.4401

\begin{abstract}
The induction of lesions in nuclear and mitochondrial DNA by cisplatin is only a small component of its cytostatic/cytotoxic activity. The signaling pathway network in the nucleus and cytoplasm may contribute to chemotherapeutic resistance. Peroxisome proliferator-activated receptor-coactivator $1 \alpha(\mathrm{PGC} 1 \alpha)$-mediated mitochondrial biogenesis regulates mitochondrial structural and the functional adaptive response against chemotherapeutic stress, and may be a therapeutic target. However, this regulatory network is complex and depends upon tumor types and environments, which require further investigation. Our previous study found that cisplatin-resistant ovarian epithelial carcinoma was more dependent on mitochondrial aerobic oxidation to support their growth, suggesting the association between mitochondrial function and chemotherapeutic resistance. In the present study, it was demonstrated that the expression of PGC1 $\alpha$ and level of mitochondrial biogenesis were higher in cisplatin-resistant SKOV3/DDP cells compared with cisplatin-sensitive SKOV3 cells. Furthermore, SKOV3/DDP cells upregulated the expression of PGC1 $\alpha$ and maintained mitochondrial structural and functional integrity through mitochondrial biogenesis under cisplatin stress. Inhibiting the expression of PGC1 $\alpha$ using short hairpin RNA led to the downregulation of mitochondrial biogenesis and high levels of apoptosis in the SKOV3/DDP cells, and cisplatin resistance was reversed in the PGCl $\alpha$ deficient SKOV3/DDP cells. Collectively, the present study
\end{abstract}

Correspondence to: Professor Jing Su or Professor Liankun Sun, Department of Pathophysiology, College of Basic Medical Sciences, Jilin University, 126 Xinmin Street, Changchun, Jilin 130021, P.R. China

E-mail: sujing@jlu.edu.cn

E-mail:sunlk@jlu.edu.cn

Key words: peroxisome proliferator-activated receptor-coactivator $1 \alpha$, mitochondrial biogenesis, oxidative phosphorylation, cisplatin resistance, ovarian cancer provided evidence that cisplatin stimulated the expression of PGC1 $\alpha$ and the upregulation of mitochondrial biogenesis through PGC1 $\alpha$, promoting cell viability and inhibiting apoptosis in response to cisplatin treatment, thus triggering cisplatin resistance in ovarian cancer cells.

\section{Introduction}

Cisplatin resistance can be provoked by drug extrusion, multidrug resistance-associated protein activity and upregulation of the DNA repair machinery. In addition, a series of adaptive responses induced by cisplatin that maintain tumor cell homeostasis and interfere with apoptotic signaling, including metabolic reprogramming, autophagy and oxidative stress, can lead to cisplatin resistance $(1,2)$. In the 1920 s, Warburg et al first observed the metabolic shift in energy in tumor cells, later termed the 'Warburg effect', in which tumor cells shift towards using aerobic glycolysis to meet energy requirements. Subsequent studies have linked this transition with mitochondrial dysfunction (3-5). Increasing evidence indicates that mitochondria, which integrate metabolism and apoptotic activities, significantly influence cancer cell survival, invasion, metastasis and drug resistance (6). Although mitochondria have their own genome, the majority of mitochondrial proteins are encoded by the nuclear genome $(7,8)$. Through the mechanism known as the nucleo-mitochondrial anterograde regulation system, these two genomes coordinately regulate mitochondrial proteostasis and maintain mitochondrial functional integrity to prevent tumor cells from environmental stress-induced damage, including chemotherapeutic stimulation (8-10). Therefore, investigating the complex machinery of the nucleo-mitochondrial anterograde regulation system is vital to clarify the mechanism underlying cell apoptosis evasion and may assist in identifying a novel anticancer therapy target to disturb mitochondrial function.

Peroxisome proliferator-activated receptor (PPAR)coactivator $1 \alpha(\mathrm{PGC} 1 \alpha)$ is a member of the PGC1 family, which functions as a transcriptional coactivator in the regulation of multiple signal transduction pathways, and acts as a principal regulator of cell metabolism and mitochondrial biogenesis (11). Accumulating evidence now suggests a link 
between PGC1 $\alpha$-mediated mitochondrial biogenesis and tumor apoptosis evasion $(12,13)$. Permuth-Wey et al found that inter-individual genetic variation in genes involved in mitochondrial biogenesis, including PGC1 $\alpha$ and nuclear respiratory factor 1 (NRF1), was most markedly associated with epithelial ovarian cancer (EOC) risk in a multi-center study of cases of EOC in Caucasian individuals and controls, and the overexpression of PGC1 $\alpha$ was associated with poor prognosis in EOC (14). In addition, in BRAF V600E-positive human melanoma, the expression of $\mathrm{PGC} 1 \alpha$ resulted in the upregulation of oxidative phosphorylation (OXPHOS) genes, energy status and mitochondrial biogenesis, accompanied by acquired BRAF inhibitor resistance (15). In addition, PGC1 $\alpha$ resisted mitogen-activated protein kinase inhibitor-induced cell apoptosis in melanoma (16). Therefore, further elucidation of the potential mechanism of the PGC1 $\alpha$-mediated upregulation of mitochondrial bioenergy and biogenesis involved in apoptotic evasion in chemotherapy-resistant tumor cell is important.

Previous studies in myocytes have found that the transcriptional activity of NRF1 and NRF2 were significantly increased following the overexpression of PGC1 $\alpha$, suggesting that PGC1 $\alpha$ may be a co-activator of NRF1 and NRF2 $(17,18)$. Other studies have shown that the PGC1 $\alpha / \mathrm{NRF} 1 / 2$-mitochondrial transcription factor A (TFAM)/mitochondrial transcription factor B1 (TFB1M) axis may be involved in the upregulation of mitochondrial mass, mitochondrial DNA (mtDNA) copy numbers and respiratory complex protein expression to promote mitochondrial biogenesis $(7,17,19,20)$. In the chemotherapeutic treatment of human colon cancer with oxaliplatin, the genes involved in OXPHOS and mitochondrial biogenesis, including PGC1 $\alpha$, were found to be markedly upregulated, suggesting that chemotherapy induced a shift in tumor metabolism from glycolysis to OXPHOS, eliciting tumor cell chemotherapeutic resistance (21). Furthermore, the sensitivity of estrogen receptor (ER)-positive breast cancer to cisplatin was reported to increase when the PGC1 $\alpha$ downstream gene TFAM was knocked down, and cisplatin resistance was restored when TFAM was reintroduced into ER-positive breast cancer cells (22). These results confirmed that the PGC1 $\alpha$-mediated mitochondrial biogenesis transcriptional pattern may engage a tumor cell apoptosis evasion mechanism in different stages of chemotherapeutic resistance.

As PGC1 $\alpha$ interacts with different transcription factors, the PGC1 $\alpha$-mediated multistep nuclear regulatory network affects cancer cell survival and death from different aspects (23-26). Therefore, to examine the action of PGC1 $\alpha$ in the evasion of apoptosis by upregulating mitochondrial bioenergy and biogenesis in ovarian cancer, the mitochondrial biogenesis-associated PGC1 $\alpha$ signaling pathway and its changes under external stimuli require examination. Our previous study demonstrated differences in mitochondrial function between cisplatin-sensitive SKOV3 ovarian cancer cells and their cisplatin-resistant clones SKOV3/DDP cells (Xu et al, unpublished data). The present study aimed to obtain further insight into PGC1 $\alpha \mathrm{G}$ to examine the role of PGC1 $\alpha$ mediated mitochondrial biogenesis in cisplatin resistance in ovarian cancer cells, which may further substantiate the role of nucleo-mitochondrial signaling communication in cell fate and provide possibilities for promising mitochondria-targeted treatment modalities for increasing cancer chemosensitivity.

\section{Materials and methods}

Reagents and antibodies. Cisplatin and 3-(4,5-dimetrylthiazol-2-yl)-2,5-diphenyltetrazolium bromide (MTT) were purchased from Sigma-Aldrich; EMD Millipore (Billerica, MA, USA). Enhanced chemiluminescence (ECL) reagents were from Thermo Fisher Scientific, Inc. (Waltham, MA USA). The following antibodies were used: Anti-PGC1 $\alpha$ (cat. no. A12348), anti-NRF1 (cat. no. A5246), anti-NRF2 (cat. no. A12306) and anti-TFAM (cat. no. A1926) from ABclonal Biotech Co., Ltd. (Boston, MA, USA); anti- $\beta$ actin (cat. no. 60008-1-Ig), anti-B-cell lymphoma 2 (Bcl-2; cat. no. 12789-1-AP), anti-Bcl-2-associated X protein (Bax; cat. no. 50599-2-Ig), anti-cytochrome $c$ oxidase subunit 5a (COX5A; cat. no. 11448-1-AP), peroxidase-conjugated AffiniPure goat anti-mouse IgG (H+L; cat. no. SA00001-1), and peroxidase-conjugated AffiniPure goat anti-rabbit IgG (H+L; cat. no. SA00001-2) from ProteinTech Group, Inc. (Chicago, IL, USA); anti-caspase-3 (cat. no. ab32351), and anti-voltage-dependent anion-selective channel 1 (VDAC1; cat. no. ab14734) from Abcam (Cambridge, MA, USA); anti-myeloid cell leukemia 1 (Mcl-1; cat. no. sc-12756), anti-translocase of mitochondrial outer membrane complex 20 (TOM20; cat. no. sc-17764), and anti-cytochrome $c$ (cat. no. sc-13561) from Santa Cruz Biotechnology, Inc. (Santa Cruz, CA, USA).

Cell culture. The cisplatin-sensitive SKOV3 ovarian carcinoma cells and their cisplatin-resistant clone SKOV3/DDP cells were obtained from the Chinese Academy of Medical Sciences and Peking Union Medical College (Beijing, China). The two cell lines were maintained at $37^{\circ} \mathrm{C}$ in a $5 \% \mathrm{CO}_{2}$ and $95 \%$ air atmosphere in Roswell Park Memorial Institute-1640 culture medium (Gibco; Thermo Fisher Scientific, Inc.) supplemented with $10 \%$ fetal bovine serum (FBS; Invitrogen; Thermo Fisher Scientific, Inc.), $100 \mathrm{U} / \mathrm{ml}$ penicillin and $100 \mathrm{U} / \mathrm{ml}$ streptomycin. The cisplatin-resistant SKOV3/DDP cells were cultured in the presence of $1 \mu \mathrm{g} / \mathrm{ml}$ cisplatin in RPMI-1640 culture medium at $37^{\circ} \mathrm{C}$ to maintain resistance.

Cellular viability assays. Cellular viability was measured using MTT assays. The cells were seeded in 96-well plates at a density of $1 \times 10^{4}$ cells/well. Following exposure of the cells to cisplatin, $20 \mu \mathrm{l}$ of MTT solution $(5 \mathrm{mg} / \mathrm{ml})$ was added to each well and the cells were incubated for $4 \mathrm{~h}$. DMSO (Beijing Chemical Industry Co., Ltd., Beijing, China) was then added to the wells to solubilize the formazan products following elimination of the media. The absorbance was recorded at $570 \mathrm{~nm}$ using a CLARIOstar microplate reader (BMG Labtech $\mathrm{GmbH}$, Offenburg, Germany). The growth inhibition rate was calculated as follows: Inhibition $(\%)=[1-($ absorbance of experimental group / absorbance of control group)] x100.

Flow cytometric analysis. JC-1 (cat. no. C2005; Beyotime Institute of Biotechnology, Haimen, China) was used to monitor the integrity of mitochondria and fluorescent mitochondria dye MitoTracker ${ }^{\mathrm{TM}}$ Green FM (cat. no. M7514; Invitrogen; Thermo Fisher Scientific, Inc.) was used to detect the mass of mitochondria. Exponentially growing SKOV3 and SKOV3/DDP cells were seeded in 6-well culture plates at a 
density of $2 \times 10^{5}$ cells/well. Following exposure to different experimental conditions, the cells were trypsinized and resuspended in 1640 medium with $10 \%$ FBS at a concentration of $1 \times 10^{6}$ cells $/ \mathrm{ml}$. The cells were incubated with JC-1 $(5 \mu \mathrm{g} / \mathrm{ml})$ or MitoTracker ${ }^{\mathrm{TM}}$ Green $(100 \mathrm{~nm})$ in the dark at room temperature for $20 \mathrm{~min}$. The samples were examined using the BD Accuri ${ }^{\mathrm{TM}}$ C6 Plus personal flow cytometer (BD Biosciences, Franklin Lakes, NJ, USA).

Transmission electron microscopy. Electron microscopy and morphometric analysis were performed as described previously (27). The cells were fixed for $30 \mathrm{~min}$ with ice-cold $2.5 \%$ glutaraldehyde in $0.1 \mathrm{M}$ cacodylate buffer, embedded in Epon, and processed for transmission electron microscopy by standard procedures. Representative areas were selected for ultra-thin sectioning $(70 \mathrm{~nm})$ and examined on a transmission electron microscope at x20,000 magnification.

Immunofluorescence staining and confocal laser microscopy. The cells were seeded onto coverslips in 24-well plates $\left(5 \times 10^{4}\right.$ cells/well) overnight and exposed to different experimental conditions. Following incubation with MitoTracker ${ }^{\mathrm{TM}}$ Red CMXRos (cat. no. 7512; Invitrogen; Thermo Fisher Scientific, Inc.) for $30 \mathrm{~min}$, the cells were washed with cold PBS three times, fixed with $4 \%$ (w/v) paraformaldehyde for 20 min and washed with cold PBS three times. The cells were then stained with Hoechst $33342(1 \mu \mathrm{g} / \mathrm{ml})$ for $5 \mathrm{~min}$ and then washed three times with PBS. Following mounting, images were captured using an Olympus FV1000 confocal laser microscope (Olympus Corporation, Tokyo, Japan).

Western blot analysis. The cells subjected to the different treatments were harvested, washed twice with cold PBS, and then gently scraped into $120 \mu \mathrm{l}$ of RIPA buffer. The cell lysates were sonicated for $30 \mathrm{sec}$ on ice and then lysed at $4^{\circ} \mathrm{C}$ for $45 \mathrm{~min}$. The cell lysates were centrifuged at $3,000 \mathrm{x}$ g for $15 \mathrm{~min}$ at $4{ }^{\circ} \mathrm{C}$, and supernatant protein concentrations were determined using the BCA Protein assay kit (Pierce; Thermo Fisher Scientific, Inc.). For western blot analysis, equivalent quantities of lysate proteins (30-50 $\mu \mathrm{g}$ ) were separated by $12 \% \mathrm{w} / \mathrm{v}$ SDS-polyacrylamide gel electrophoresis and transferred onto immobilon-P transfer membranes (EMD Millipore). The membranes were blocked with $5 \%(\mathrm{w} / \mathrm{v})$ skim milk in buffer of PBST, containing $10 \mathrm{mM}$ Tris- $\mathrm{HCl}$ (pH 7.6), $100 \mathrm{mM} \mathrm{NaCl}$ and $0.1 \%(\mathrm{v} / \mathrm{v})$ Tween-20, for $1 \mathrm{~h}$ at room temperature, then incubated with the desired primary antibody (anti-PGC1 $\alpha, 1: 1,000$ dilution; anti-NRF1, 1:1,000 dilution; anti-NRF2, 1:1,000 dilution; anti-TFAM 1:1,000 dilution; anti- $\beta$-actin, 1:1,000 dilution; anti-Bcl-2, 1:1,000 dilution; anti-Bax, 1:1,000 dilution; anti-COX5A, 1:1,000 dilution; anti-caspase-3, 1:1,000 dilution; anti-VDAC1, 1:1,000 dilution; anti-Mcl-1, 1:200 dilution; anti-TOM20, 1:200 dilution and anti-cytochrome $c, 1: 200$ dilution) overnight at $4^{\circ} \mathrm{C}$. The following day, the membranes were washed with PBST and incubated with the horseradish peroxidase-conjugated secondary antibodies (1:2,000; ProteinTech Group, Inc.) for $1 \mathrm{~h}$ at room temperature. Following washing the membranes with PBST, immunodetection was performed using ECL reagent (Thermo Fisher Scientific, Inc.) and visualized using a Syngene Bio Imaging (Synoptics, Cambridge, UK). The protein levels were quantified by densitometry using
Table I. Primers for reverse transcription-quantitative polymerase chain reaction analysis.

Gene name Primer sequences

$\begin{array}{ll}\text { GAPDH } & \text { F: 5'-GGAGCGAGATCCCTCCAAAAT-3' } \\ & \text { R: 5'-GGCTGTTGTCATACTTCTCATGG-3' }\end{array}$

PPARGC1A F: 5'-TGAAGACGGATTGCCCTCATT-3' R: 5'-GCTGGTGCCAGTAAGAGCTT-3'

NRF1 F: 5'-AGGAACACGGAGTGACCCAA-3' R: 5'-TGCATGTGCTTCTATGGTAGC-3'

GABPA F: 5'-TTAAACCTGCGGACACTGTTG-3' R: 5'-GTATCCCAAGGCGTTCTTGTT-3'

TFAM F: 5'-GCTCAGAACCCAGATGCAAAA-3' R: 5'-GCCACTCCGCCCTATAAGC-3'

TFB1M F: 5'-AGAGACTTGCAGCCAATACAGG-3' R: 5'-GTGTCGAACATTGCAGAGGTA-3'

ATP5A1 F: 5'-GTATTGCCCGCGTACATGG-3' R: 5'-AGGACATACCCTTTAAGCCTGA-3'

VDAC1 F: 5'-ACGTATGCCGATCTTGGCAAA-3' R: 5'-TCAGGCCGTACTCAGTCCATC-3'

BCL2 F: 5'-GGTGGGGTCATGTGTGTG-3' R: 5'-CGGTTCAGGTACTCAGTCATCC-3'

18s rRNA F: 5'-TAGAGGGACAAGTGGCGTTC-3' R: 5'-CGCTGAGCCAGTCAGTGT-3'

ND1 R: 5'-TGGCCATGGGATTGTTGTTAA-3'

F, forward; R, reverse; PPARGC1A, peroxisome proliferator-activated receptor-coactivator $1 \alpha$; NRF, nuclear respiratory factor; GABPA, GA-binding protein transcription factor- $\alpha$; TFAM, mitochondrial transcription factor A; TFB1M, mitochondrial transcription factor B1; VDAC1, voltage-dependent anion-selective channel 1; BCL2, B-cell lymphoma 2; ND1, nicotinamide adenine dinucleotide dehydrogenase 1 .

Quantity One version 4.6.2 software (Bio-Rad Laboratories, Inc.), normalized to $\beta$-actin.

Reverse transcription-quantitative polymerase chain reaction $(R T-q P C R)$ analysis. Total cellular RNA was extracted using TRIzol $^{\mathrm{TM}}$ reagent (Invitrogen; Thermo Fisher Scientific, Inc.), reverse transcription was performed to generate cDNA, which was then amplified by RT-qPCR. The sequences of the primers used are listed in Table I. RT-qPCR analysis, containing $0.2 \mu \mathrm{g}$ cDNA, $0.2 \mu \mathrm{M}$ forward primer, $0.2 \mu \mathrm{M}$ reverse primer, $10 \mu \mathrm{l}$ qPCR SuperMix and total volume to $20 \mu \mathrm{l}$, was performed using TransStart Top Green qPCR SuperMix (cat. no. AQ131, TransGen Biotech Co., Ltd., Beijing, China) in the following conditions: $94.0^{\circ} \mathrm{C}$ for $30 \mathrm{sec}, 40$ cycles of $94.0^{\circ} \mathrm{C}$ for $5 \mathrm{sec}$ and $60.0^{\circ} \mathrm{C}$ for $30 \mathrm{sec}$. A melting curve was detected between 60 and $94^{\circ} \mathrm{C}$ to confirm the PCR product of interest. Each sample was analyzed in triplicate in the CFX96 Touch $^{\mathrm{TM}}$ Real-Time PCR detection system (Bio-Rad Laboratories, Inc.). The relative expression was calculated using the $2^{-\Delta \Delta \mathrm{Ca}}$ method (28) among 
the different experimental groups normalized to the expression of GAPDH.

PGCla knockdown by short hairpin (sh)RNA. shRNA sequences targeting human $\mathrm{PGC} 1 \alpha \mathrm{G}$ and a non-target sequence were constructed by GeneChem Co., Ltd. (Shanghai, China). The PGC1 $\alpha$ shRNA sequences were 5'-GTT-ATA-CCT-GTGATG-CTT-T-3' and 5'-CAG-CGA-AGA-TGA-AAG-TGA-T-3' and the non-target shRNA (Scramble) sequence was 5'-TTC-TCC-GAA-CGT-GTC-ACG-T-3'. Transfections with the shRNAs were performed using TurboFect ${ }^{\mathrm{TM}}$ transfection reagent (Thermo Fisher Scientific, Inc.) according to the manufacturer's protocol. Briefly, the SKOV3/DDP cells were plated in 6-well plates and transfected the following day with $4 \mu \mathrm{g}$ of PGC1 $\alpha$-shRNA or shScramble using $6 \mu 1$ of transfection reagent. The cells were harvested $24 \mathrm{~h}$ following transfection, and whole cell lysates were isolated for western blot and RT-qPCR analyses. For cellular viability, the transfected cells were treated with cisplatin for $24 \mathrm{~h}$ and then analyzed by MTT assays.

Determination of the relative mtDNA copy number. Total cellular DNA was extracted from $1 \times 10^{6}$ cells using the TIANamp Genomic DNA kit (Tiangen Biotech Co., Ltd., Beijing, China). qPCR for mitochondrial DNA content was determined using TransStart Top Green qPCR SuperMix (TransGen Biotech Co. Ltd.) for measuring the mitochondrialencoded nicotinamide adenine dinucleotide dehydrogenase 1 (ND1) relative to nuclear-encoded gene 18S rRNA (18S), as described previously $(29,30)$. The reactions, containing $0.2 \mu \mathrm{g}$ DNA, $0.2 \mu \mathrm{M}$ forward primer, $0.2 \mu \mathrm{M}$ reverse primer, $10 \mu \mathrm{l}$ TransStart Top Green qPCR SuperMix and total volume to $20 \mu$ l, were performed using the CFX96 Touch $^{\text {TM }}$ Real-Time PCR detection system (Bio-Rad Laboratories, Inc.) in the following conditions: $94.0^{\circ} \mathrm{C}$ for $30 \mathrm{sec}, 40$ cycles of $94.0^{\circ} \mathrm{C}$ for $5 \mathrm{sec}$ and $60.0^{\circ} \mathrm{C}$ for $30 \mathrm{sec}$. A melting curve was detected between 60 and $94^{\circ} \mathrm{C}$ to confirm the PCR product of interest. Each sample was analyzed in triplicate and analyzed using Bio-Rad CFX Manager 3.0 software. The relative mtDNA copy number was calculated as the ratio of the level of amplification obtained for ND1, vs. 18S (primer sequences listed in Table I) for each sample, and was normalized to the control group.

Oxygen consumption rate (OCR). The cellular OCR was measured using the MitoXpress ${ }^{\circledR}$ Xtra-Oxygen Consumption assay (Luxcel Biosciences, Cork, Ireland) using a CLARIOstar microplate reader (BMG Labtech $\mathrm{GmbH}$ ). Briefly, the SKOV3 cells were plated at $8 \times 10^{4}$ cells/well in 96-well plates and the SKOV3/DDP cells were plated at $6 \times 10^{4}$ cells/well in 96-well plates (clear-bottom, black-body plates) and allowed to adhere overnight. The reaction was maintained at $37^{\circ} \mathrm{C}$ with a plate block heater. The culture medium was removed from all wells and replaced with $160 \mu \mathrm{l}$ of prewarmed mixed liquid comprising $10 \mu \mathrm{l}$ reconstituted medium MitoXpress ${ }^{\circledR}$ Xtra reagent, $10 \mu \mathrm{l}$ cisplatin (final concentration of 6 or $30 \mu \mathrm{g} / \mathrm{ml}$ ) and $140 \mu \mathrm{l}$ fresh culture media to each well. The wells were sealed by adding two drops of pre-warmed HS mineral oil as recommended by the manufacturer. Fluorescence decay was measured kinetically immediately in the microplate reader at $37^{\circ} \mathrm{C}$ in time-resolved fluorescence (TR-F) mode using a standard filter set as follows, $380 \mathrm{~nm}$ excitation and $650 \mathrm{~nm}$ emission filters.

Mitochondrial isolation and protein extraction. Mitochondrial isolation was performed using the Minute ${ }^{\mathrm{TM}}$ Mitochondria Isolation kit (cat. no. MP-007; Invent Biotechnologies, Inc., Plymouth, MN, USA) according to the manufacturer's protocol. The isolated mitochondria was lysed in $0.5 \%(\mathrm{v} / \mathrm{v})$ Triton X-100 in calcium-free PBS for western blot analysis with antibodies against $\beta$-actin, VDAC1 and cytochrome $c$ to detect the release of cytochrome $c$.

Statistical analysis. Data are representative of three independent experiments each performed in triplicate. Statistical analysis of the data was performed using a one-way analysis of variance on IBM SPSS version 22.0 (IBM SPSS, Armonk, NY, USA). Tukey's post hoc test was used to determine the significance for all pairwise comparisons of interest. $\mathrm{P}<0.05$ was considered to indicate a statistically significant difference.

\section{Results}

PGCl $\alpha$-mediated mitochondrial biogenesis is upregulated in cisplatin-resistant ovarian cancer cells. Previous studies have shown that SKOV3/DDP ovarian cancer cells are resistant to cisplatin compared with SKOV3 cells (31), and SKOV3/DDP cells are more inclined to mitochondrial aerobic oxidation to sustain cellular processes (Xu et al, unpublished data). As shown in Fig. $1 \mathrm{~A}$, the $\mathrm{IC}_{50}$ values of SKOV3 and SKOV3/DDP cells were determined as 6 and $30 \mu \mathrm{g} / \mathrm{ml}$, respectively. To further characterize the effect of cisplatin resistance on mitochondria, the mitochondrial mass and volume in cells were examined using transmission electron microscopy. Higher numbers and a larger volume of mitochondria were observed in the SKOV3/DDP cells compared with the SKOV3 cells (Fig. 1B). In addition, mitochondria were stained using the fluorescent mitochondria dye MitoTracker ${ }^{\mathrm{TM}}$ Green to detect the mass of mitochondria using flow cytometry. As shown in Fig. 1C, the fluorescence intensity of the SKOV3/DDP cells was significantly higher than that of the SKOV3 cells, indicating that the SKOV3/DDP cells had higher mitochondria content than the SKOV3 cells. As there is a positive correlation between mitochondrial mass and mtDNA copy numbers (32), the present study subsequently examined the mtDNA copy numbers in the cell lines by qPCR. The relative mtDNA copy number of the SKOV3/DDP cells was higher than that of the SKOV3 cells (Fig. 1D), suggesting that the SKOV3/DDP cells had a higher level of mitochondrial biogenesis than the SKOV3 cells.

Based on the above results, the present study subsequently examined the mitochondrial biogenesis regulatory pathway in these two cell lines. The gene and protein expression levels of mitochondrial biogenesis-related signaling molecules were examined using RT-qPCR and western blot analyses. It was found that the gene expression levels of NRF1, GA-binding protein transcription factor- $\alpha$ (GABPA), TFAM and TFB1M were higher in the SKOV3/DDP cells than in the SKOV3 cells (Fig. 2A). Consistent with these findings, the protein expression levels of PGC1 $\alpha$, NRF1, NRF2, TFAM, VDAC1 and COX5A 

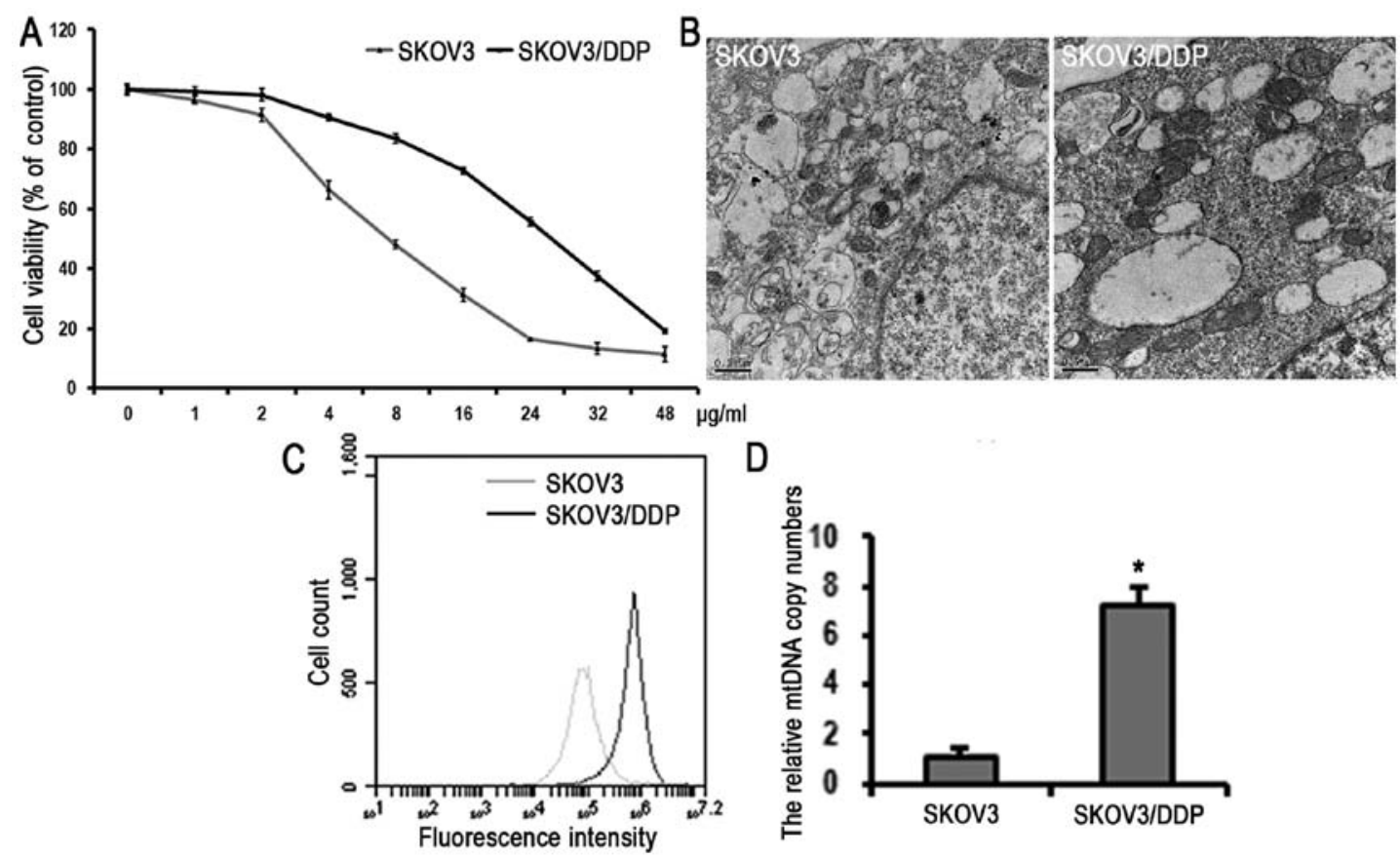

Figure 1. Differences in mitochondrial biogenesis status between SKOV3 and SKOV3/DDP cells. (A) SKOV3 and SKOV3/DDP cells were treated with varying doses of cisplatin for $24 \mathrm{~h}$. Cell viability was determined using a 3-(4,5-dimetrylthiazol-2-yl)-2,5-diphenyltetrazolium bromide assay (mean \pm standard deviation, $\mathrm{n}=3$ ). (B) Representative transmission electron microscopy photomicrographs of SKOV3 and SKOV3/DDP cells (scale bar=500 nm). (C) Mitochondrial mass of SKOV3 and SKOV3/DDP cells were determined by staining with MitoTracker ${ }^{\mathrm{TM}}$ Green and detected using flow cytometry. (D) Relative mtDNA copy numbers in SKOV3 and SKOV3/DDP cells were determined by the DNA ratios of ND1 and 18S and detected by quantitative polymerase chain reaction analysis (mean \pm standard deviation, $\mathrm{n}=3$; " $\mathrm{P}<0.05$, vs. SKOV3. SKOV3/DDP, cisplatin-resistant SKOV3 cells; mtDNA, mitochondrial DNA; PGC1 $\alpha$, peroxisome proliferator-activated receptor-coactivator $1 \alpha$.
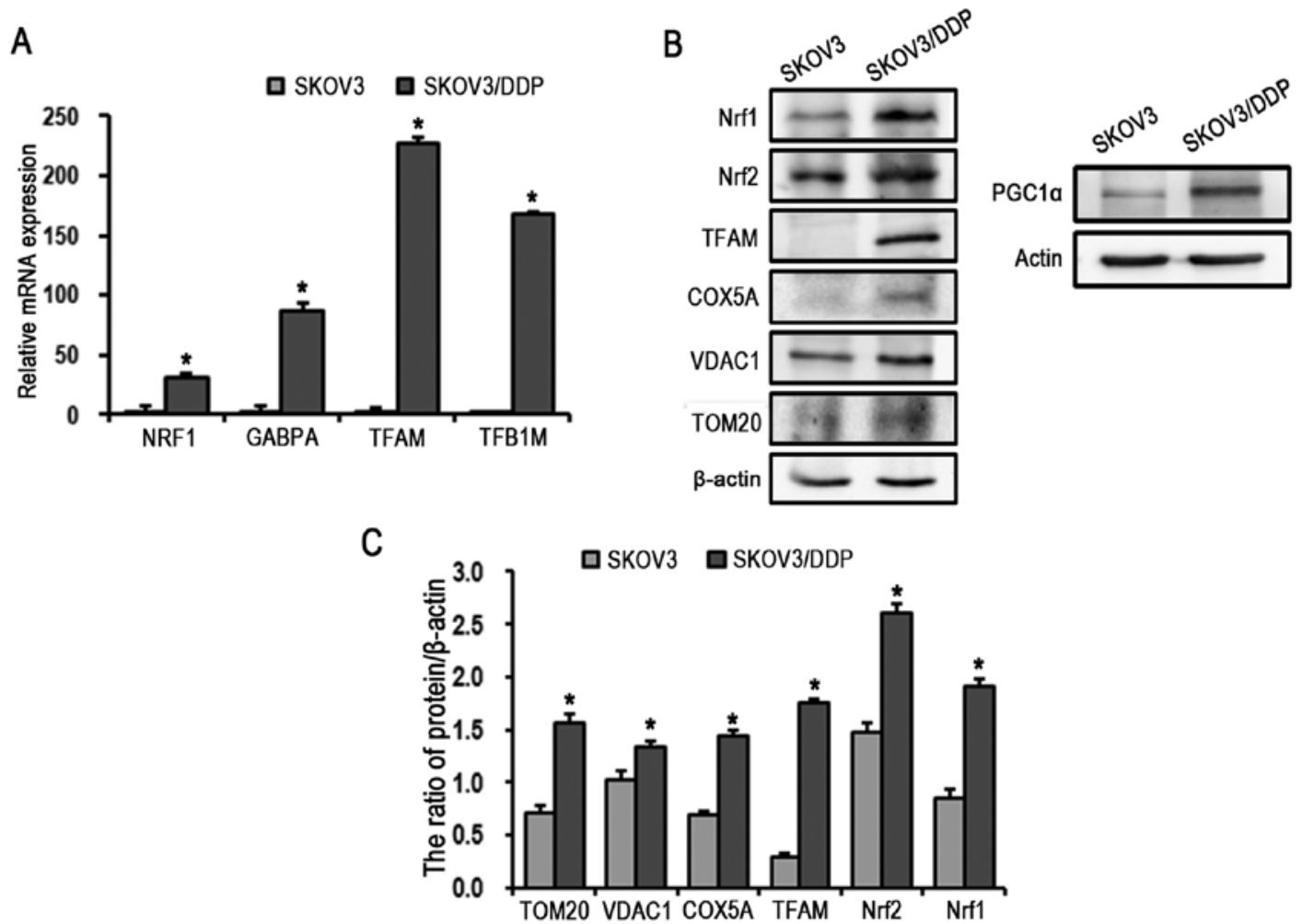

Figure 2. Discrepancies in the levels of PGC1 $\alpha$ downstream molecules between SKOV3 and SKOV3/DDP cells. (A) Reverse transcription-quantitative polymerase chain reaction detection of PGC1 $\alpha$ downstream genes in SKOV3 and SKOV3/DDP cells (mean \pm standard deviation, $\mathrm{n}=3$; ${ }^{*} \mathrm{P}<0.05$, vs. SKOV3). (B) Western blot detection of PGCl $\alpha$, and PGC1 $\alpha$ downstream proteins and mitochondrial proteins in SKOV3 and SKOV3/DDP cells. (C) Quantitation of PGCl $\alpha$ downstream and mitochondrial protein levels (mean \pm standard deviation, $n=3$; ${ }^{*} \mathrm{P}<0.05$, vs. SKOV3). SKOV3/DDP, cisplatin-resistant SKOV3 cells; PGC1 $\alpha$, peroxisome proliferator-activated receptor-coactivator $1 \alpha$; GABPA, GA-binding protein transcription factor- $\alpha$ A; TFAM, mitochondrial transcription factor A; TFB1M, mitochondrial transcription factor B1; TOM20, translocase of mitochondrial outer membrane complex 20; VDAC1, voltage-dependent anion-selective channel 1; COX5A, cytochrome $c$ oxidase subunit $5 \mathrm{a}$. 
A

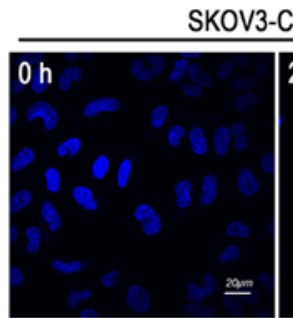

SKOV3-Cisplatin
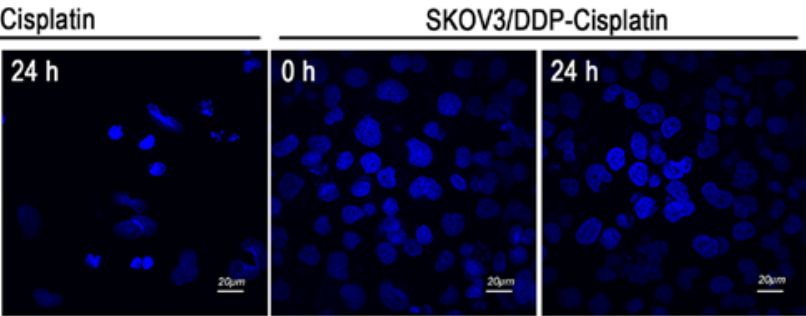

B

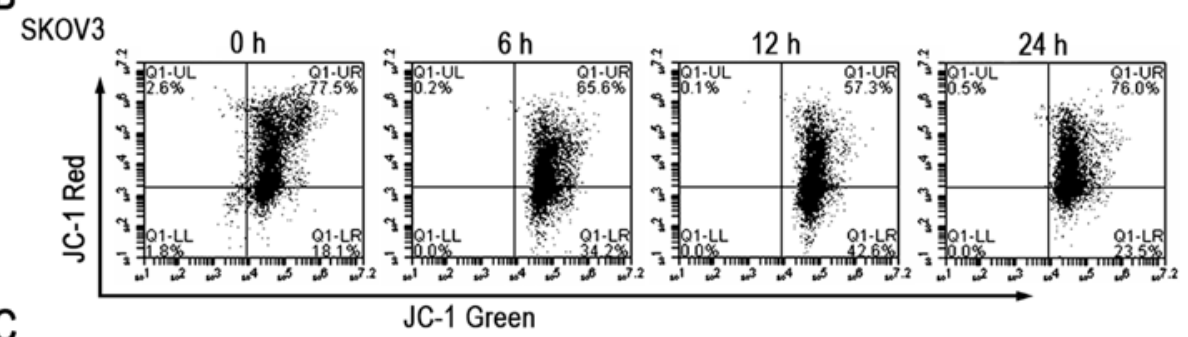

C

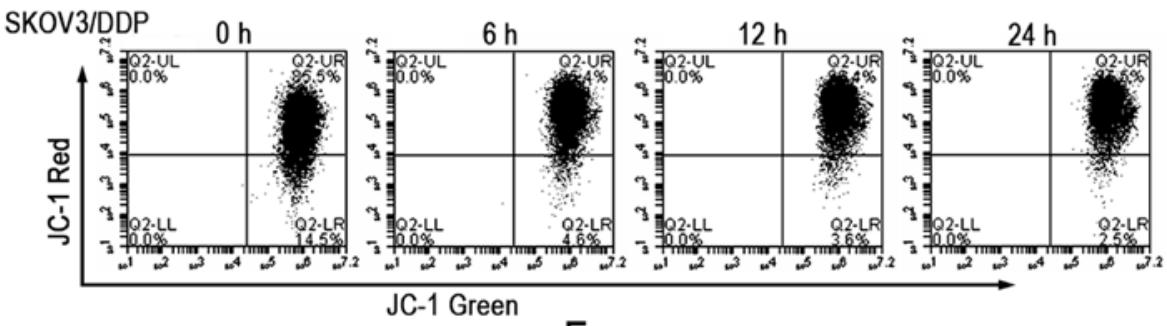

D

E

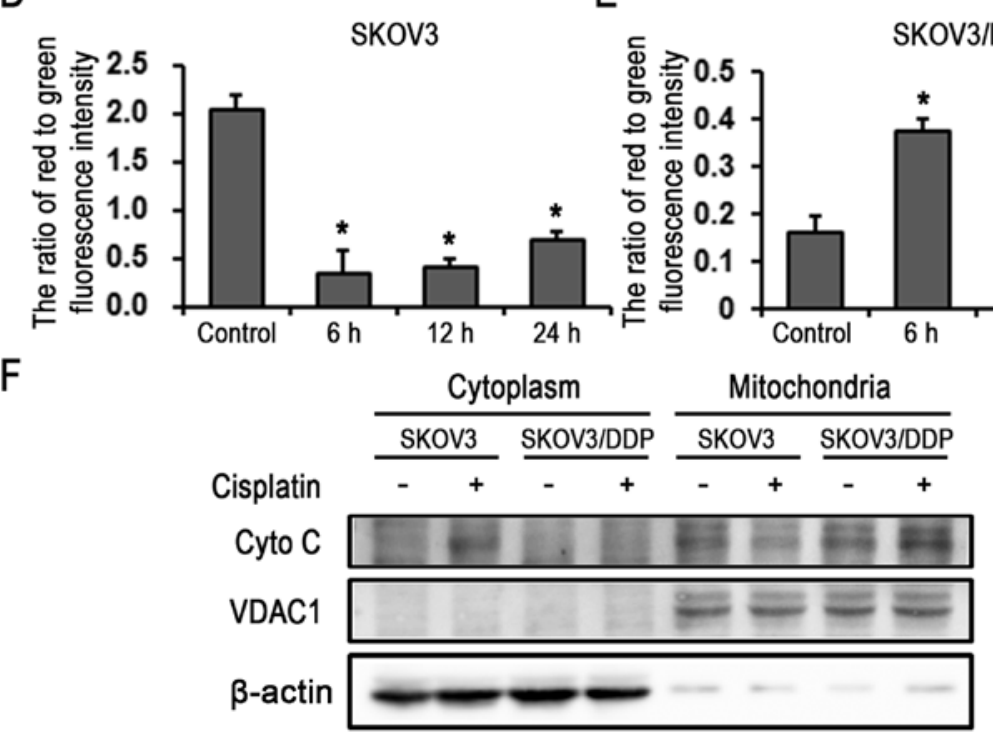

Figure 3. Cisplatin induces mitochondrial apoptosis in SKOV3 cells, but not in SKOV3/DDP cells. (A) Apoptotic chromatin condensation staining with Hoechst 33342 was observed by confocal microscopy in SKOV3 and SKOV3/DDP cells treated with $6 \mu \mathrm{g} / \mathrm{ml}$ cisplatin for $24 \mathrm{~h}$ (scale bar, $20 \mu \mathrm{m}$ ). Mitochondrial membrane potential staining with JC-1 was detected by flow cytometry in (B) SKOV3 and (C) SKOV3/DDP cells. Quantification of the ratio of red to green fluorescence intensity for JC-1 in (D) SKOV3 and (E) SKOV3/DDP cells (mean \pm standard deviation, $\mathrm{n}=3$; ${ }^{*} \mathrm{P}<0.05$, vs. control). (F) Western blot detection of the release of Cyto C in SKOV3 and SKOV3/DDP cells treated with $6 \mu \mathrm{g} / \mathrm{ml}$ cisplatin for $24 \mathrm{~h}$. SKOV3/DDP, cisplatin-resistant SKOV3 cells; Cyto C, cytochrome $c$; VDAC1, voltage-dependent anion-selective channel 1.

were higher in the SKOV3/DDP cells than in the SKOV3 cells (Fig. 2B). These results demonstrated that the nuclear regulatory system of mitochondrial biogenesis was upregulated in the cisplatin-resistant SKOV3/DDP cells, suggesting the potential association between PGCl $\alpha$-mediated mitochondrial biogenesis and cisplatin resistance in ovarian cancer.

Cisplatin stimulates PGCl $\alpha$-mediated mitochondrial biogenesis in cisplatin-resistant ovarian cancer cells. Previous results indicated that SKOV3/DDP cells underwent reduced apoptosis, compared with SKOV3 cells treated with cisplatin for $24 \mathrm{~h}$ (33). In the present study, using confocal microscopy, apoptotic chromatin condensation was examined in SKOV3 and SKOV3/DDP cells treated with cisplatin $(6 \mu \mathrm{g} / \mathrm{ml})$ for $24 \mathrm{~h}$ with Hoechst 33342 staining. Treatment with cisplatin induced apoptotic chromatin condensation in the SKOV3 cells, whereas no significant changes were observed in the SKOV3/DDP cells (Fig. 3A). Changes in the mitochondrial 

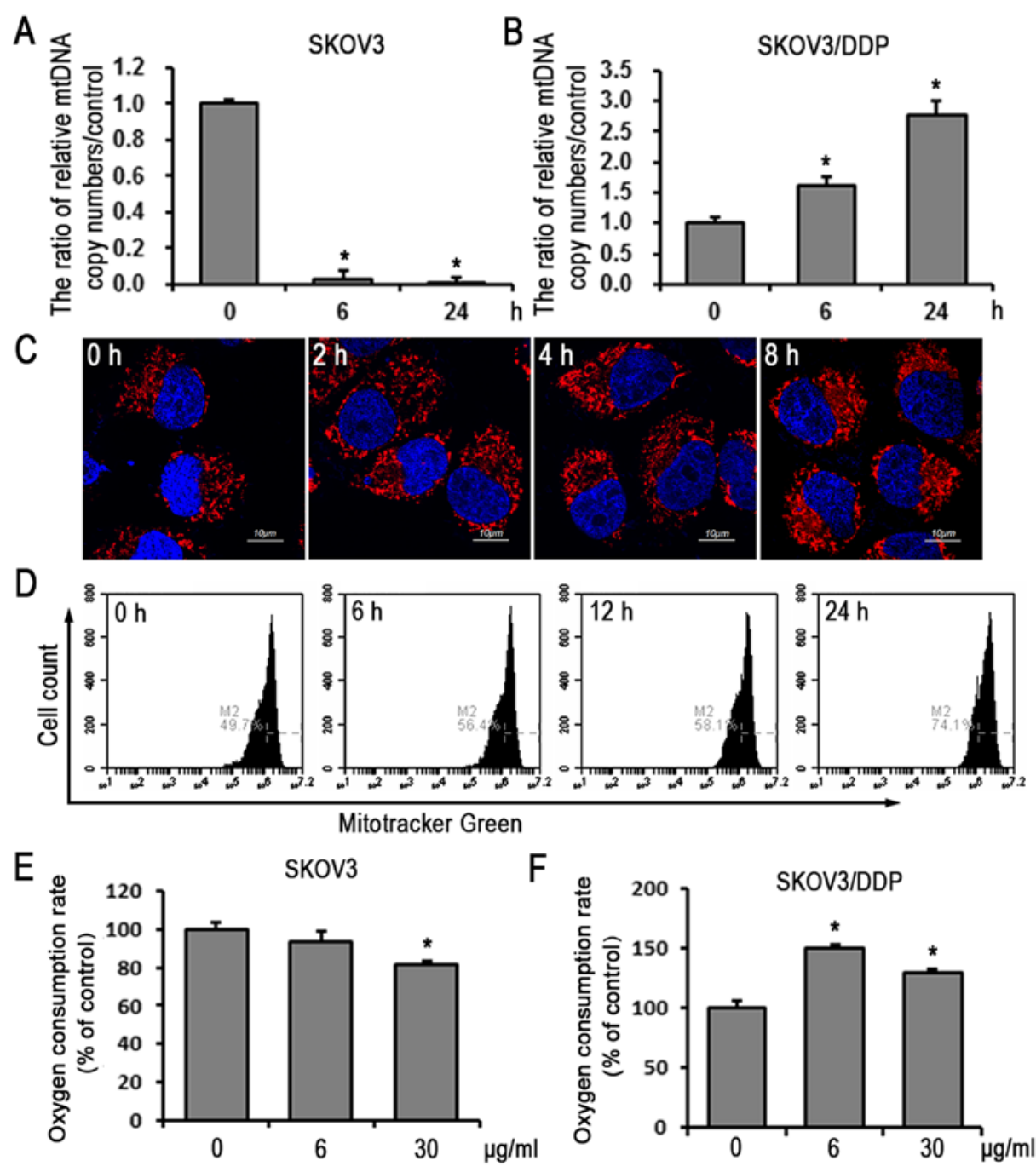

Figure 4. Cisplatin promotes mitochondrial biogenesis in SKOV3/DDP cells. Relative mtDNA copy numbers were detected by quantitative polymerase chain reaction analysis in (A) SKOV3 and (B) SKOV3/DDP cells treated with $6 \mu \mathrm{g} / \mathrm{ml}$ cisplatin (mean \pm standard deviation, $\mathrm{n}=3$; ${ }^{*} \mathrm{P}<0.05$, vs. control). (C) Mitochondrial mass staining with MitoTracker ${ }^{\mathrm{TM}}$ Red was observed with confocal laser microscopy in SKOV3/DDP cells (scale bar=10 $\mu \mathrm{m}$ ) treated with cisplatin for 2, 4 and $8 \mathrm{~h}$. (D) Changes in mitochondrial mass staining with MitoTracker ${ }^{\mathrm{TM}}$ Green was detected by flow cytometry in SKOV3/DDP cells treated with cisplatin for 6,12 and $24 \mathrm{~h}$. Cellular oxygen consumption rate of (E) SKOV3 and (F) SKOV3/DDP cells treated with 6 or $30 \mu \mathrm{g} / \mathrm{ml}$ cisplatin (mean \pm standard deviation, $\mathrm{n}=3 ;{ }^{*} \mathrm{P}<0.05$, vs. control). SKOV3/DDP, cisplatin-resistant SKOV3 cells; mtDNA, mitochondrial DNA.

membrane potential occur during the early stages of apoptosis, therefore, the present study evaluated the mitochondrial outer membrane integrity using JC- 1 and flow cytometry in the cell lines treated with cisplatin $(6 \mu \mathrm{g} / \mathrm{ml})$ for various durations $(0,6,12$ and $24 \mathrm{~h})$. The results showed that cisplatin induced mitochondrial depolarization in the SKOV3 cells, but not in the SKOV3/DDP cells (Fig. 3B-D), suggesting that ovarian cancer cisplatin-resistant cells maintained mitochondrial structure stability under cisplatin stress. Western blot analysis was also used to detect the release of cytochrome $c$ in SKOV3 and SKOV3/DDP cells treated with $6 \mu \mathrm{g} / \mathrm{ml}$ cisplatin for $24 \mathrm{~h}$. Cisplatin induced the release of cytochrome $c$ in SKOV3 cells, but not in SKOV3/DDP cells (Fig. 3E), indicating the occurrence of apoptosis in the cisplatin-sensitive cells.

To further clarify the role of mitochondrial biogenesis in the response to cisplatin-induced apoptosis, the present study examined the mtDNA copy numbers in the two cell lines treated with cisplatin $(6 \mu \mathrm{g} / \mathrm{ml})$ for 0,3 and $24 \mathrm{~h}$. The mtDNA copy number was increased in the SKOV3/
DDP cells in a time-dependent manner, compared with that in the SKOV3 cells (Fig. 4A and B). The mitochondrial mass of the SKOV3/DDP cells treated with cisplatin $(6 \mu \mathrm{g} / \mathrm{ml})$ for various $0,2,4$ and $8 \mathrm{~h}$ was then examined using MitoTracker ${ }^{\mathrm{TM}}$ Red staining and confocal microscopy. In addition, MitoTracker ${ }^{\mathrm{TM}}$ Green staining and flow cytometry were used to examine SKOV3/DDP cells treated with cisplatin $(6 \mu \mathrm{g} / \mathrm{ml})$ for $0,6,12$ and $24 \mathrm{~h}$. These results showed that the fluorescence intensity increased in a timedependent manner in SKOV3/DDP cells (Fig. 4C and D), demonstrating that cisplatin-resistant ovarian cancer cells responded to cisplatin stress by increasing intracellular mitochondrial mass. Extracellular OCR was then evaluated. As shown in Fig. 4E and F, cisplatin induced an increase of OCR in SKOV3/DDP cells and decreased OCR in SKOV3 cells, indicating that, in response to cisplatin, cisplatinresistant cells not only maintain mitochondrial mass and integrity, but also enhance mitochondrial function to overcome cisplatin-induced cytotoxic effects. 
A
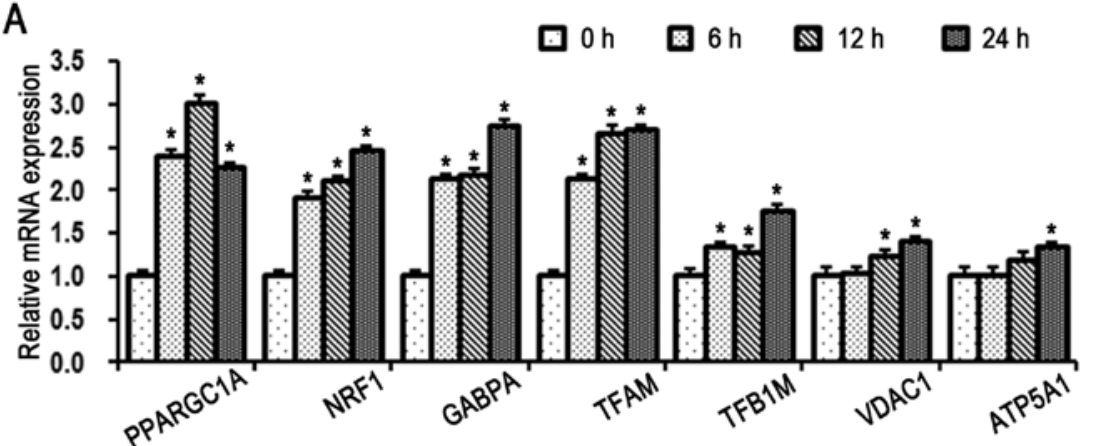

B

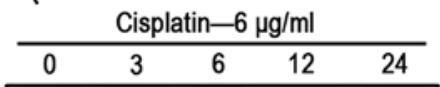

C

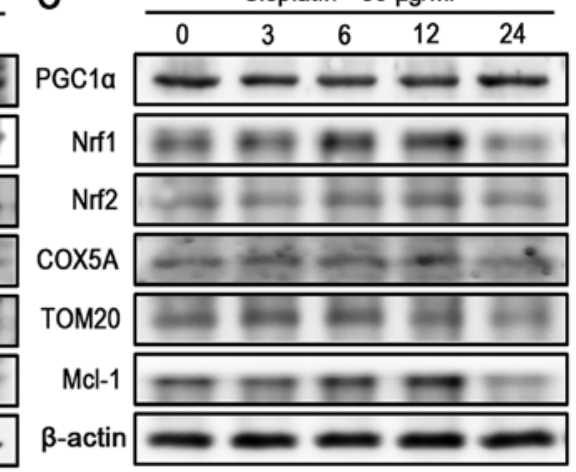

PGC1a

Nrf1

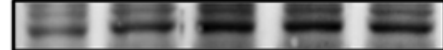

PGC10

Nif2
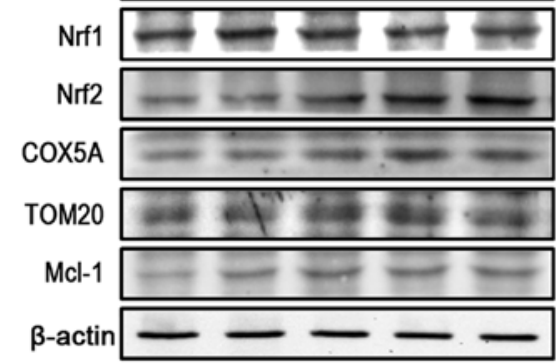

D
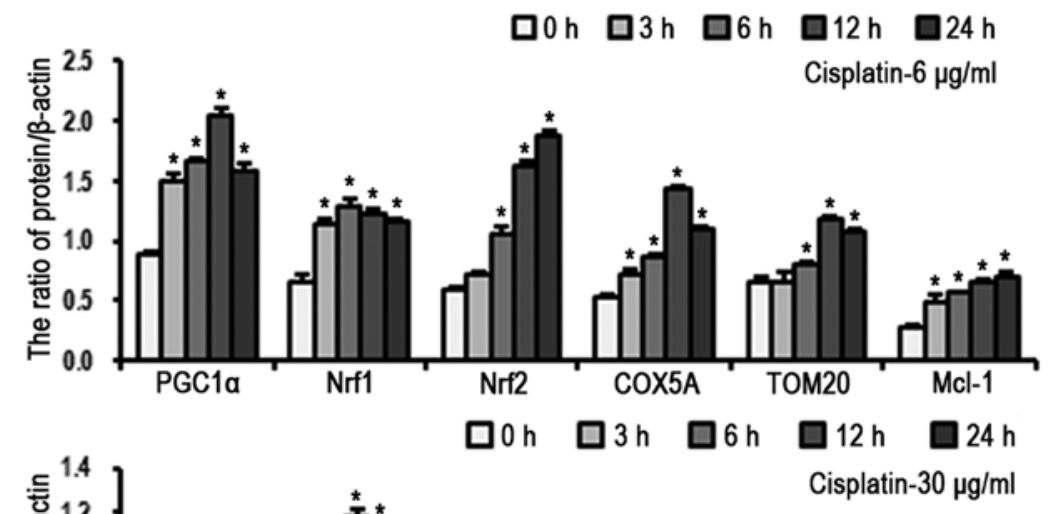

E

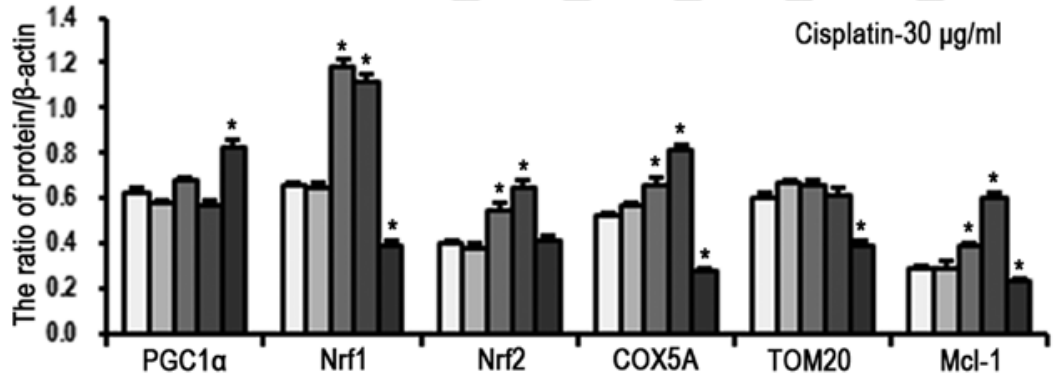

Figure 5. Cisplatin activates the PGC1 $\alpha$ signaling pathway in SKOV3/DDP cells. (A) mRNA levels of PGC1 $\alpha$ signal pathway components and mitochondrial proteins in SKOV3/DDP cells treated with cisplatin $(6 \mu \mathrm{g} / \mathrm{ml})$ by reverse transcription-quantitative polymerase chain reaction analysis (mean \pm standard deviation, $\mathrm{n}=3$; ${ }^{*} \mathrm{P}<0.05$, vs. control). Western blot detection of PGC1 $\alpha$ signaling pathway and mitochondrial proteins in SKOV3/DDP cells treated with (B) $6 \mu \mathrm{g} / \mathrm{ml}$ and (C) $30 \mu \mathrm{g} / \mathrm{ml}$ cisplatin. Quantitation of PGC1 $\alpha$ signaling pathway and mitochondrial protein levels in cells treated with (D) $6 \mu \mathrm{g} / \mathrm{ml}$ and (E) $30 \mu \mathrm{g} / \mathrm{ml}$ cisplatin (mean \pm standard deviation, $\mathrm{n}=3$; ${ }^{*} \mathrm{P}<0.05$, vs. control). SKOV3/DDP, cisplatin-resistant SKOV3 cells; PGC1 $\alpha$, peroxisome proliferatoractivated receptor-coactivator $1 \alpha$; NRF, nuclear respiratory factor; GABPA, GA-binding protein transcription factor- $\alpha$ A; TFAM, mitochondrial transcription factor A; TFB1M, mitochondrial transcription factor B1; TOM20, translocase of mitochondrial outer membrane complex 20; VDAC1, voltage-dependent anion-selective channel 1; COX5A, cytochrome $c$ oxidase subunit 5a; Mcl-1, myeloid cell leukemia 1.

Taken together the results of the present study indicated that, in response to cisplatin stress, SKOV3/DDP cells maintained the mass, stability and function of mitochondria, however, how the upstream regulatory pathway is involved in mitochondrial biogenesis remained to be elucidated. The results of RT-qPCR analysis revealed that the gene expression levels of PGC1 $\alpha$, NRF1, GABPA and mitochondrial-related genes increased in SKOV3/DDP cells treated with cisplatin $(6 \mu \mathrm{g} / \mathrm{ml})$ in a time-dependent manner (Fig. 5A). The expression of mitochondrial biogenesis-related signaling molecules were then evaluated in SKOV3/DDP cells (Fig. 5B-E) treated with cisplatin for various times $(0,3,6,12$ and $24 \mathrm{~h})$. At a cisplatin concentration of $6 \mu \mathrm{g} / \mathrm{ml}$, the protein levels of PGC1 $\alpha \mathrm{P}$ NRF1 and NRF2 gradually increased with the increase of exposure 

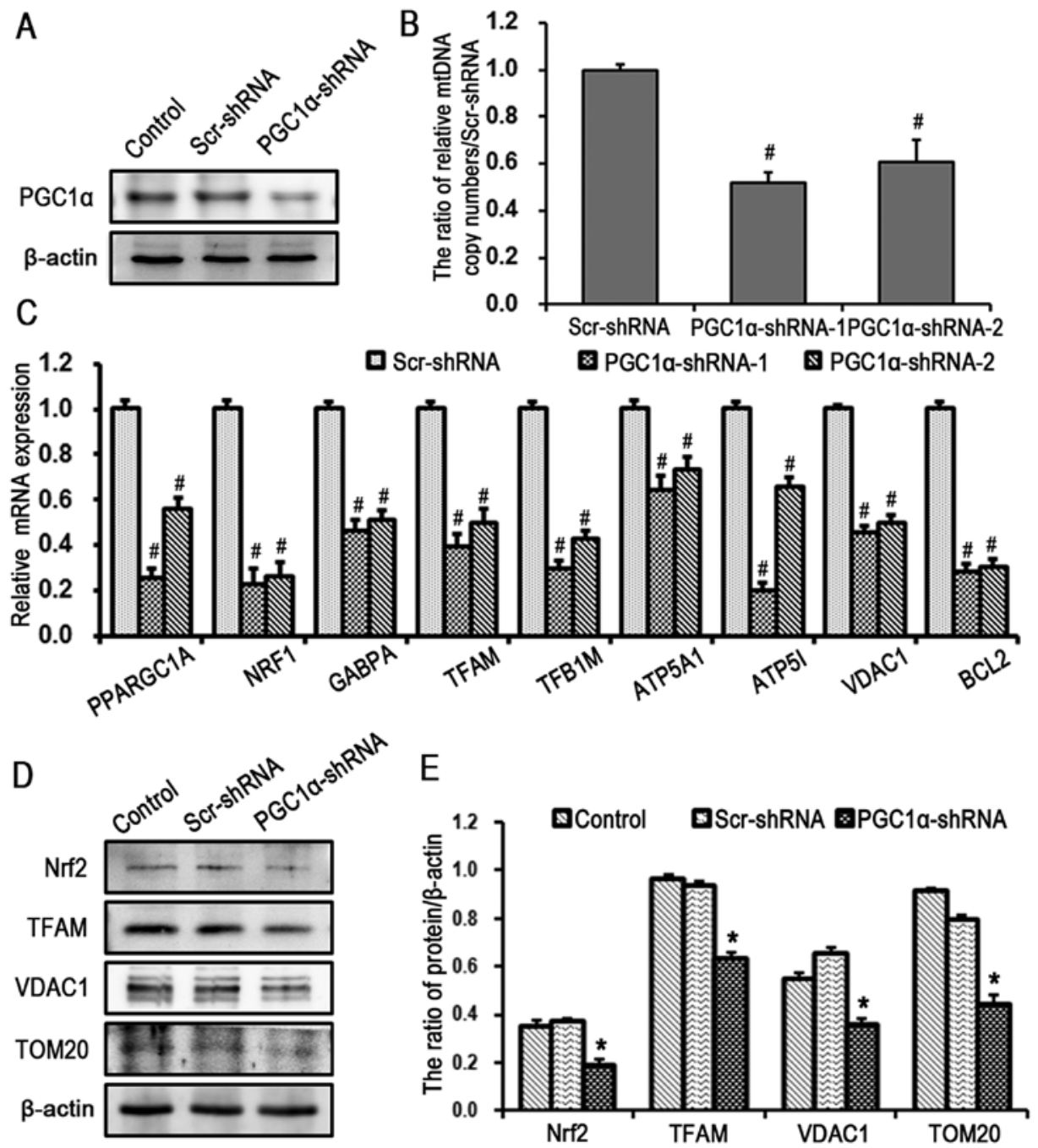

Figure 6. Knockdown of PGCl $\alpha$ decreases mitochondrial biogenesis in SKOV3/DDP cells. (A) Western blot analysis of the knockdown efficiency of PGC1 $\alpha$. (B) Relative mtDNA copy numbers were detected using qPCR analysis in SKOV3/DDP cells transfected with shRNA for $24 \mathrm{~h}$ (mean \pm standard deviation, $\mathrm{n}=3$; "P<0.05, vs. Scr-shRNA). (C) RT-qPCR analysis of mRNA levels of PGC1 $\alpha$ signaling pathway and mitochondrial genes in SKOV3/DDP cells transfected with shRNA for $24 \mathrm{~h}$ (mean \pm standard deviation, $\mathrm{n}=3$; ${ }^{*} \mathrm{P}<0.05$, vs. Scr-shRNA). (D) Western blot detection of mitochondrial biogenesis proteins in SKOV3/ DDP cells. (E) Quantitation of mitochondrial biogenesis protein levels (mean \pm standard deviation, $n=3$; ${ }^{*} \mathrm{P}<0.05$, vs. control). SKOV/DDP, cisplatin-resistant SKOV cells; PGCl $\alpha$, peroxisome proliferator-activated receptor-coactivator $1 \alpha$; NRF, nuclear respiratory factor; GABPA, GA-binding protein transcription factor- $\alpha$ A TFAM, mitochondrial transcription factor A; TFB1M, mitochondrial transcription factor B1; VDAC1, voltage-dependent anion-selective channel 1; BCL2, B-cell lymphoma 2; shRNA, short hairpin RNA; Scr, scrambled; mtDNA, mitochondrial DNA; RT-qPCR, reverse transcription-quantitative polymerase chain reaction.

to cisplatin treatment; cisplatin also enhanced the expression of mitochondrial proteins TFAM, TOM20 and COX5A, but did not alter the levels of activated caspase-3 (Fig. 5B and D). Protein levels in response to a high dose of cisplatin $(30 \mu \mathrm{g} / \mathrm{ml})$ in SKOV3/DDP cells were also examined. Of note, the expression of PGC1 $\alpha$ gradually increased in a time-dependent manner (0-12 h), but then decreased at $24 \mathrm{~h}$ compared with the controls (Fig. 5C and E), which may be due to PGC1 $\alpha$ mediated mitochondrial biogenesis being unable to function against the cisplatin-induced toxicity effect on mitochondria.

These above results demonstrated that cisplatin activated the PGC1 $\alpha$-mediated mitochondrial biogenesis signaling pathway, and maintained the structure and function integrity of mitochondria in SKOV3/DDP cells, with an upregulation of PGC1 $\alpha$. This suggested that the PGC1 $\alpha$ pathway may be involved in the mechanism of cisplatin resistance in ovarian cancer cisplatin-resistant cells.
Knockdown of PGCla by shRNA decreases mitochondrial biogenesis and increases sensitivity to cisplatin in SKOV3/DDP cells. To further evaluate the action of PGC1 $\alpha$ in cisplatin resistance of ovarian cancer cells, PGC1 $\alpha$ was knocked down in SKOV3/DDP cells by transient transfection with shRNA, with the protein expression of PGC1 $\alpha$ shown to be downregulated (Fig. 6A). The mtDNA copy number was significantly decreased in the PGC1 $\alpha$-shRNA knockdown group, compared with that in the Scr-shRNA group (Fig. 6B). It was also observed that the expression levels of PGC1 $\alpha$ and PGC1 $\alpha$-related genes were decreased in the PGC1 $\alpha$-shRNA knockdown group, compared with those in the Scr-shRNA group (Fig. 6C). Consistent with these results, the protein levels of PGC1 $\alpha$, NRF2, TFAM, VDAC1 and TOM20 were decreased in the PGC1 $\alpha$-shRNA knockdown group (Fig. 6D and E). Furthermore, the level of apoptosis was increased following the knockdown of PGC1 $\alpha$ in SKOV3/DDP cells, as reflected 


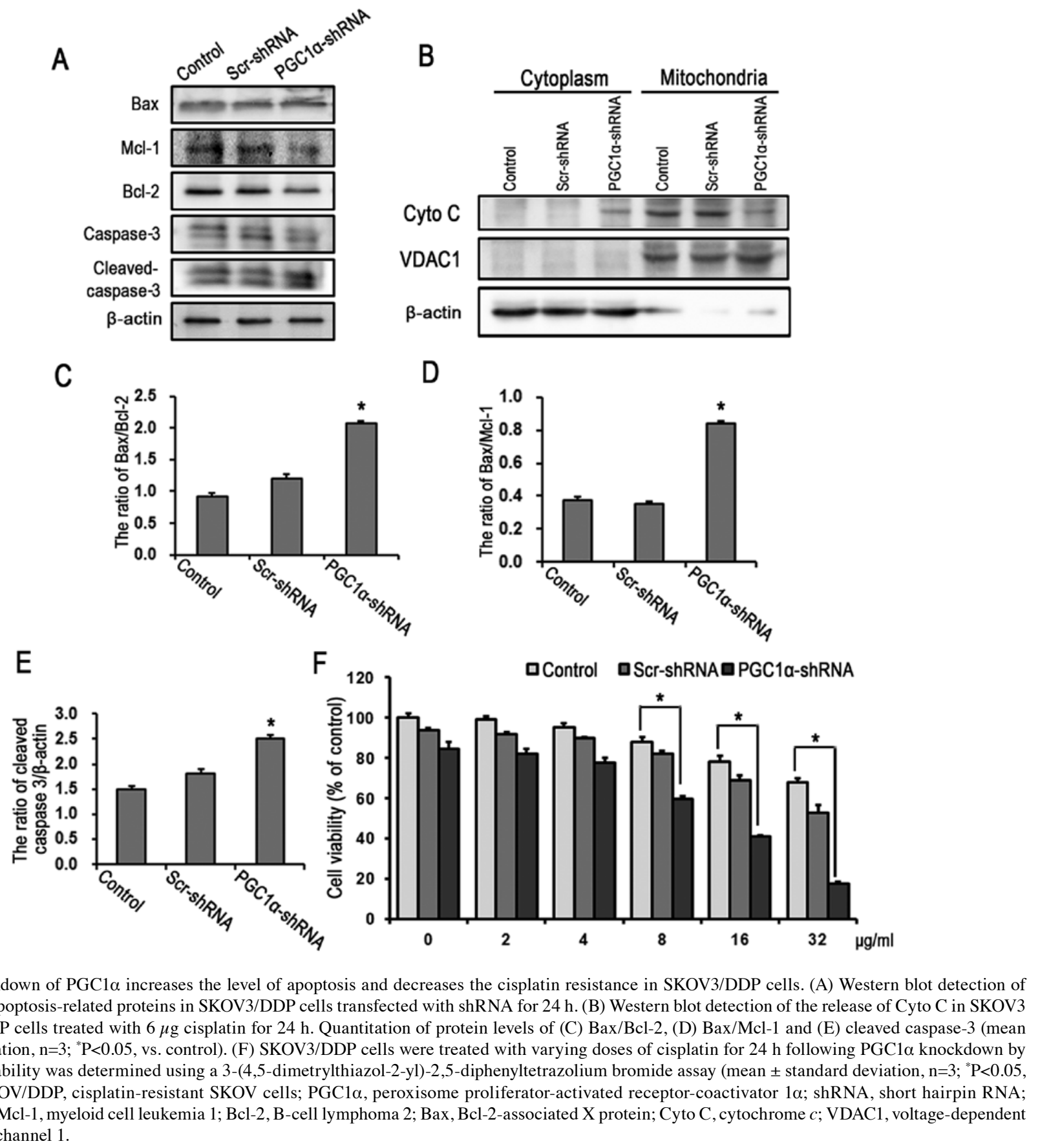

Figure 7. Knockdown of PGCl $\alpha$ increases the level of apoptosis and decreases the cisplatin resistance in SKOV3/DDP cells. (A) Western blot detection of mitochondrial apoptosis-related proteins in SKOV3/DDP cells transfected with shRNA for $24 \mathrm{~h}$. (B) Western blot detection of the release of Cyto C in SKOV3 and SKOV3/DDP cells treated with $6 \mu \mathrm{g}$ cisplatin for $24 \mathrm{~h}$. Quantitation of protein levels of (C) Bax/Bcl-2, (D) Bax/Mcl-1 and (E) cleaved caspase-3 (mean \pm standard deviation, $\mathrm{n}=3$; ${ }^{*} \mathrm{P}<0.05$, vs. control). (F) SKOV3/DDP cells were treated with varying doses of cisplatin for $24 \mathrm{~h}$ following PGCl $\alpha$ knockdown by shRNA. Cell viability was determined using a 3-(4,5-dimetrylthiazol-2-yl)-2,5-diphenyltetrazolium bromide assay (mean \pm standard deviation, $\mathrm{n}=3$; ${ }^{*} \mathrm{P}<0.05$, vs. control). SKOV/DDP, cisplatin-resistant SKOV cells; PGC1 $\alpha$, peroxisome proliferator-activated receptor-coactivator 1 $\alpha$; shRNA, short hairpin RNA; Scr, scrambled; Mcl-1, myeloid cell leukemia 1; Bcl-2, B-cell lymphoma 2; Bax, Bcl-2-associated X protein; Cyto C, cytochrome $c$; VDAC1, voltage-dependent anion-selective channel 1.

in the increase of activated caspase-3, the decreased ratios of anti-apoptotic proteins Bcl-2 and Mcl-1 to pro-apoptotic protein Bax, and the release of cytochrome $c$ (Fig. 7A-E). No significant differences were observed between the Scr-shRNA group and the controls. The MTT assay demonstrated that the knockdown of PGCl $\alpha$ increased in the SKOV3/DDP cell sensitivity to cisplatin $\left(\mathrm{IC}_{50}\right.$ of $\left.14.6 \mu \mathrm{g} / \mathrm{ml}\right)$ compared with that in the control and Scr-shRNA groups (Fig. 7F).

The above results indicated that the deficiency of PGCl $\alpha$ in SKOV3/DDP cells resulted in downregulation of the mitochondrial biogenesis signaling pathway and reductions in the mass and function of mitochondria, resulting in increased sensitivity to cisplatin. These results further verified the hypothesis that, in response to cisplatin stress, ovarian cancer cisplatinresistant cells show upregulated expression of PGC1 $\alpha$ and activation of the mitochondrial biogenesis signaling pathway, which contributes to cisplatin resistance by maintaining the abundance and functional integrity of mitochondria.

\section{Discussion}

Cisplatin resistance remains a major obstacle in the clinical treatment of ovarian cancer (34). Increasing evidence indicates that, in addition to DNA lesions, complex signal pathways in the nucleus and cytoplasm can be involved in the cisplatin resistance mechanism $(1,2)$. Vellinga et al showed that chemotherapy induced the upregulation of PGCl $\alpha$ signaling pathway-dependent respiratory complex protein and enhanced the OCR in colon cancer and, under this condition, the cancer cells survived cisplatin cytotoxicity through transforming 
tumor metabolism from aerobic glycolysis to OXPHOS (21). Similar to these findings, our previous study revealed that cisplatin-resistant SKOV3/DDP ovarian cancer cells were more dependent on mitochondrial aerobic oxidation to support their growth (Xu et al, unpublished data), and the expression of PGC1 $\alpha$, a crucial regulator of mitochondrial biogenesis, was significantly higher in SKOV3/DDP cells than SKOV3 cells (Fig. 1E). Transmission electron microscopy and flow cytometry showed that the mass and volume of mitochondria were larger in SKOV3/DDP cells than in SKOV3 cells (Fig. 1B and C). It was also found that the mtDNA copy number was higher in SKOV3/DDP cells than in SKOV3 cells (Fig. 1D). Collectively, these results demonstrate a higher level of mitochondrial biogenesis in cisplatin-resistant ovarian cancer cells and suggested an association between the high level of mitochondrial energy metabolism and the cisplatin resistance mechanism.

Treatment strategies targeting mitochondria metabolic function in cancer cells have gained wide acceptance $(35,36)$, and earlier studies have shown that the overexpression of PGCl $\alpha$ restores the intracellular oxidative metabolism and ATP content, which prevents cell death by enhancing bioenergy homeostasis and the antioxidant defense system. Even if PGC1 $\alpha$ is overexpressed, the OCR cannot be restored with knockout of NRF1 and NRF2 (37). Of note, there are discrepancies in PGCl $\alpha$ in tumor cells of different histologic origin, and the overexpression of PGClais not beneficial in all cases. LaGory et al found that, under hypoxia, the downregulation of the PGCl $\alpha /$ estrogen-related receptor $\alpha$ axis induced tumor chemotherapy resistance in renal cell carcinoma (38), suggesting the specific effect of PGCl $\alpha$ depends on the cellular environment and the interaction of PGC1 $\alpha$ with different molecules. Therefore, the present study focused on the PGC1 $\alpha /$ NRF1/2-axis-regulated mitochondrial biogenesis pathway. NRF1 and NRF2 transcriptionally regulate the majority of aerobic respiratory complex proteins (39) and mtDNA transcription factors $(40,41)$, and control mitochondrial biogenesis through their interactions with PGCl $\alpha$ (42-44), which ensures the integration between the nuclear and mitochondrial genomes for mitochondrial function in a direct and indirect manner. In the present study, the gene expression levels of NRF1, GABPA TFAM and TFB1M were higher in SKOV3/ DDP cells than in SKOV3 cells (Fig. 2A), and similar results were shown for protein expression (Fig. 2B). These results demonstrated differences in the mitochondrial biogenesis status between the two cell lines, and provided preliminary data supporting a role for PGCl $\alpha$ in cisplatin resistance via regulating mitochondrial biogenesis in ovarian cancer.

Several reports have shown that an increase of mtDNA copy number, an indicator of mitochondrial biogenesis, is associated with poor prognosis in colorectal cancer, gastric cancer and lymphoblastic leukemia glioma (45-47). The present study found that the mtDNA copy number in SKOV3/DDP cells gradually increased with cisplatin exposure duration, whereas the copy number in SKOV3 cells decreased (Fig. 4A and B). With the increase of mitochondrial mass (Fig. 4C and D), the OCR of SKOV3/DDP cells also increased under cisplatin treatment, and that of SKOV3 cells decreased (Fig. 4E and F). At the molecular level, cisplatin promoted the gene and protein expression of PGC1 $\alpha$, and upregulated the PGC1 $\alpha$-mediated mitochondrial biogenesis pathway (Fig. 5). The JC-1 staining and flow cytometry revealed that the SKOV3/DDP cells maintained mitochondrial integrity on exposure to cisplatin, as reflected in the high mitochondrial membrane potential, but not in SKOV3 cells (Fig. 3B and C), leading to the release of cytochrome $c$ and chromatin condensation in SKOV3 cells. These results demonstrated that cisplatin-resistant and non-resistant ovarian cancer cells show distinct responses to cisplatin stimulation, with differences in the mass and integrity of mitochondria in the two cells, eventually leading to differences in mitochondrial function and cell fate.

To further clarify the role of PGCl $\alpha$ in cisplatin-resistant ovarian cancer cells, knockdown assays were performed through transient transfection with shRNA. The mtDNA copy number and PGCl $\alpha$-mediated mitochondrial biogenesis pathway were decreased upon PGC1 $\alpha$ knockdown (Fig. 6). The majority of Bcl-2 family proteins are located in the mitochondrial outer membrane through the carboxy-terminal transmembrane domain, whereas the localization and function of Bcl-2 family anti-apoptotic proteins are regulated by the protein and lipids in the mitochondrial outer membrane (48). In addition to the Bcl-2 family proteins involved in regulation of the mitochondrial localization of Bax, several other receptors with components involved in mitochondrial transport mechanisms, including the TOM complex, and mitochondrial carrier homolog 2, facilitate Bcl-2 family protein localization in the mitochondrial outer membrane (49). The results of the present study showed that, following knockdown of PGC1 $\alpha$, the ratio of anti-apoptotic proteins (Bcl-2 and Mcl-1) and pro-apoptotic protein (Bax) in the SKOV3/DDP cells were significantly reduced (Fig. 7A and C-E), as was the release of cytochrome $c$, which supported the hypothesis that PGCl $\alpha$ affects the localization and function of Bcl-2 family proteins and the level of mitochondrial apoptosis through mitochondrial biogenesis. Finally, consistent with this hypothesis, the cell viability decreased in response to cisplatin following the knockdown of PGCl $\alpha$ (Fig. 7F), suggesting that the cisplatin-resistant ovarian cancer cells upregulate mitochondrial bioenergy and biogenesis against cisplatin toxicity depending on the action of PGCl $\alpha$ and its signaling pathway.

However, there numerous questions remain unanswered. The present study observed that the expression of PGCl $\alpha$ was increased, however, the expression of its downstream protein were decreased following a high dose of cisplatin for $24 \mathrm{~h}$ in the SKOV3/DDP cells (Fig. 5C). There are two possible reasons for these observations, one of which is that cisplatin-induced mitochondrial toxicity exceeded the supplementation of PGCl $\alpha$-mediated mitochondrial biogenesis or, under the toxic effect of cisplatin, PGCl $\alpha$ may initiate other unknown signal pathways triggering cell death. As discussed above, PGCl $\alpha$ may be involved in different cellular process depending upon its interaction with different molecules under various cellular environments.

Mitochondrial targeting offers additional possibilities for cancer therapy, including the inhibition of mitochondrial metabolism, interruption of mitochondria protein location or destruction of mitochondrial membrane structure. However, overcoming biologic barriers and accurate location are major challenges for targeting mitochondrial therapy (50). Although research has suggested the potential application of 
nanocarriers to deliver agents, further investigation is required in the clinical setting.

Collectively, the results of the present study provided evidence that cisplatin activated PGC1 $\alpha$-mediated mitochondrial biogenesis in cisplatin-resistant ovarian cancer cells, which led to the maintenance of mitochondrial mass and functional stability, and enhanced the mitochondrial anti-apoptotic capacity. Upon depletion of PGC1 $\alpha$ in the cisplatin-resistant ovarian cancer cells, mitochondrial biogenesis decreased, followed by a decrease in mitochondrial stability and function; in these conditions, the anti-apoptotic capacity was unable to respond to cisplatin toxicity and enhanced the sensitivity of the cell to cisplatin. These data showed that PGC1 $\alpha$-mediated mitochondrial biogenesis in cisplatin-resistant cells ovarian cancer may provide a specific targeting approach for mitochondrial respiration-dependent chemotherapy-resistant tumors and alter the clinical efficacy of cisplatin via the nuclear transcription system in these tumors.

\section{Acknowledgements}

Not applicable.

\section{Funding}

This study was supported by the National Natural Science Foundation of China (grant nos. 81772794, 81472419,81672948, 81501982 and 81572927), the Jilin Provincial Research Foundation for the Development of Science and Technology Projects (grant nos. 20170623021TC and 20160414005GH) and the Jilin University Bethune Plan B Projects (grant no. 2015222).

\section{Availability of data and materials}

All data generated or analyzed during this study are included in this published article.

\section{Authors' contributions}

LS conceived and designed the experiments, performed the experiments, analyzed the data and wrote the manuscript. BS and JS performed the experiments, analyzed the data and were the major contributors in writing the manuscript. SY, YL and HX analyzed the data, prepared figures and/or tables. JS and LS conceived and designed the experiments, reviewed and edited the manuscript. All authors read and approved the final manuscript.

\section{Ethics approval and consent to participate}

Not applicable.

\section{Consent for publication}

Not applicable.

\section{Competing interests}

The authors declare that they have no competing interests.

\section{References}

1. Galluzzi L, Vitale I, Michels J, Brenner C, Szabadkai G, HarelBellan A, Castedo M and Kroemer G: Systems biology of cisplatin resistance: Past, present and future. Cell Death Dis 5: e1257, 2014.

2. Dasari S and Tchounwou PB: Cisplatin in cancer therapy: Molecular mechanisms of action. Eur J Pharmacol 740: 364-378, 2014.

3. Warburg O, Wind F and Negelein E: The metabolism of tumors in the body. J Gen Physiol 8: 519-530, 1927.

4. Warburg O: Iron, the oxygen-carrier of respiration-ferment Science 61: 575-582, 1925.

5. Warburg O: On respiratory impairment in cancer cells. Science 124: 269-270, 1956.

6. Zong WX, Rabinowitz JD and White E: Mitochondria and cancer. Mol Cell 61: 667-676, 2016.

7. Scarpulla RC: Transcriptional paradigms in mammalian mitochondrial biogenesis and function. Physiol Rev 88: 611-638, 2008.

8. Mercer TR, Neph S, Dinger ME, Crawford J, Smith MA, Shearwood AM, Haugen E, Bracken CP, Rackham O, Stamatoyannopoulos JA, et al: The human mitochondrial transcriptome. Cell 146: 645-658, 2011.

9. Quirós PM, Mottis A and Auwerx J: Mitonuclear communication in homeostasis and stress. Nat Rev Mol Cell Biol 17: 213-226, 2016.

10. Marchetti P, Guerreschi P, Mortier L and Kluza J: Integration of mitochondrial targeting for molecular cancer therapeutics. Int J Cell Biol 2015: 283145, 2015.

11. Zhang $\mathrm{Y}$ and $\mathrm{Xu} \mathrm{H}$ : Translational regulation of mitochondrial biogenesis. Biochem Soc Trans 44: 1717-1724, 2016.

12. Fernandez-Marcos PJ and Auwerx J: Regulation of PGC-1 $\alpha$, a nodal regulator of mitochondrial biogenesis. Am J Clin Nutr 93: 884 S-90, 2011

13. Tan Z, Luo X, Xiao L, Tang M, Bode AM, Dong Z and Cao Y: The role of PGC1 $\alpha$ in cancer metabolism and its therapeutic implications. Mol Cancer Ther 15: 774-782, 2016.

14. Permuth-Wey J, Chen YA, Tsai YY, Chen Z, Qu X, Lancaster JM, Stockwell H, Dagne G, Iversen E, Risch H, et al: Inherited variants in mitochondrial biogenesis genes may influence epithelial ovarian cancer risk. Cancer Epidemiol Biomarkers Prev 20: 1131-1145, 2011.

15. Haq R, Shoag J, Andreu-Perez P, Yokoyama S, Edelman H, Rowe GC, Frederick DT, Hurley AD, Nellore A, Kung AL, et al: Oncogenic BRAF regulates oxidative metabolism via PGC1 $\alpha$ and MITF. Cancer Cell 23: 302-315, 2013.

16. Gopal YN, Rizos H, Chen G, Deng W, Frederick DT, Cooper ZA, Scolyer RA, Pupo G, Komurov K, Sehgal V, et al: Inhibition of mTORC1/2 overcomes resistance to MAPK pathway inhibitors mediated by PGCl $\alpha$ and oxidative phosphorylation in melanoma. Cancer Res 74: 7037-7047, 2014.

17. Wu Z, Puigserver P, Andersson U, Zhang C, Adelmant G, Mootha V, Troy A, Cinti S, Lowell B, Scarpulla RC, et al: Mechanisms controlling mitochondrial biogenesis and respiration through the thermogenic coactivator PGC-1. Cell 98: 115-124, 1999.

18. Puigserver $\mathrm{P}$ and Spiegelman BM: Peroxisome proliferatoractivated receptor-gamma coactivator 1 alpha (PGC-1 alpha): Transcriptional coactivator and metabolic regulator. Endocr Rev 24: 78-90, 2003.

19. Gleyzer N, Vercauteren K and Scarpulla RC: Control of mitochondrial transcription specificity factors (TFB1M and TFB2M) by nuclear respiratory factors (NRF-1 and NRF-2) and PGC-1 family coactivators. Mol Cell Biol 25: 1354-1366, 2005.

20. Scarpulla RC: Nuclear control of respiratory chain expression by nuclear respiratory factors and PGC-1-related coactivator. Ann N Y Acad Sci 1147: 321-334, 2008.

21. Vellinga TT, Borovski T, de Boer VC, Fatrai S, van Schelven S, Trumpi K, Verheem A, Snoeren N, Emmink BL, Koster J, et al: SIRT1/PGC1 $\alpha$-dependent increase in oxidative phosphorylation supports chemotherapy resistance of colon cancer. Clin Cancer Res 21: 2870-2879, 2015.

22. Gao W, Wu MH, Wang N, Ying MZ, Zhang YY, Hua J, Chuan L and Wang YJ: Mitochondrial transcription factor A contributes to cisplatin resistance in patients with estrogen receptor-positive breast cancer. Mol Med Rep 14: 5304-5310, 2016.

23. Bhalla K, Hwang BJ, Dewi RE, Ou L, Twaddel W, Fang HB, Vafai SB, Vazquez F, Puigserver P, Boros L, et al: PGC1a promotes tumor growth by inducing gene expression programs supporting lipogenesis. Cancer Res 71: 6888-6898, 2011. 
24. Vazquez F, Lim JH, Chim H, Bhalla K, Girnun G, Pierce K, Clish CB, Granter SR, Widlund HR, Spiegelman BM, et al: PGC1 $\alpha$ expression defines a subset of human melanoma tumors with increased mitochondrial capacity and resistance to oxidative stress. Cancer Cell 23: 287-301, 2013.

25. Do MT, Kim HG, Choi JH and Jeong HG: Metformin induces microRNA-34a to downregulate the Sirt1/Pgc-1 $\alpha /$ Nrf2 pathway, leading to increased susceptibility of wild-type p53 cancer cells to oxidative stress and therapeutic agents. Free Radic Biol Med 74: 21-34, 2014.

26. Jones AW, Yao Z, Vicencio JM, Karkucinska-Wieckowska A and Szabadkai G: PGC-1 family coactivators and cell fate: Roles in cancer, neurodegeneration, cardiovascular disease and retrograde mitochondria-nucleus signalling. Mitochondrion 12: 86-99, 2012.

27. Han W, Li L, Qiu S, Lu Q, Pan Q, Gu Y, Luo J and Hu X: Shikonin circumvents cancer drug resistance by induction of a necroptotic death. Mol Cancer Ther 6: 1641-1649, 2007.

28. Livak KJ and Schmittgen TD: Analysis of relative gene expression data using real-time quantitative PCR and the 2(-Delta Delta C(T)) Method. Methods 25: 402-408, 2001.

29. Eaton JS, Lin ZP, Sartorelli AC, Bonawitz ND and Shadel GS Ataxia-telangiectasia mutated kinase regulates ribonucleotide reductase and mitochondrial homeostasis. J Clin Invest 117: 2723-2734, 2007.

30. Lebedeva MA, Eaton JS and Shadel GS: Loss of p53 causes mitochondrial DNA depletion and altered mitochondrial reactive oxygen species homeostasis. Biochim Biophys Acta 1787: 328-334, 2009

31. Yu H, Su J, Xu Y, Kang J, Li H, Zhang L, Yi H, Xiang X, Liu F and Sun L: p62/SQSTM1 involved in cisplatin resistance in human ovarian cancer cells by clearing ubiquitinated proteins Eur J Cancer 47: 1585-1594, 2011.

32. Medeiros DM: Assessing mitochondria biogenesis. Methods 46 : 288-294, 2008.

33. Ma L, Xu Y, Su J, Yu H, Kang J, Li H, Li X, Xie Q, Yu C, Sun L, et al: Autophagic flux promotes cisplatin resistance in human ovarian carcinoma cells through ATP-mediated lysosomal function. Int J Oncol 47: 1890-1900, 2015.

34. Agarwal R and Kaye SB: Ovarian cancer: Strategies for overcoming resistance to chemotherapy. Nat Rev Cancer 3: 502-516, 2003.

35. Schulze A and Harris AL: How cancer metabolism is tuned for proliferation and vulnerable to disruption. Nature 491: 364-373, 2012.

36. Pan Y, Cao M, Liu J, Yang Q, Miao X, Go VLW, Lee PWN and Xiao GG: Metabolic regulation in mitochondria and drug resistance. Adv Exp Med Biol 1038: 149-171, 2017.

37. Shao D, Liu Y, Liu X, Zhu L, Cui Y, Cui A, Qiao A, Kong X, Liu Y, Chen Q, et al: PGC-1 beta-regulated mitochondrial biogenesis and function in myotubes is mediated by NRF-1 and ERR alpha. Mitochondrion 10: 516-527, 2010.
38. LaGory EL, Wu C, Taniguchi CM, Ding CC, Chi JT, von Eyben R, Scott DA, Richardson AD and Giaccia AJ: Suppression of PGC-1 $\alpha$ is critical for reprogramming oxidative metabolism in renal cell carcinoma. Cell Reports 12: 116-127, 2015.

39. Cam H, Balciunaite E, Blais A, Spektor A, Scarpulla RC, Young R, Kluger Y and Dynlacht BD: A common set of gene regulatory networks links metabolism and growth inhibition. Mol Cell 16: 399-411, 2004

40. Kelly DP and Scarpulla RC: Transcriptional regulatory circuits controlling mitochondrial biogenesis and function. Genes Dev 18: 357-368, 2004.

41. Scarpulla RC: Nuclear activators and coactivators in mammalian mitochondrial biogenesis. Biochim Biophys Acta 1576: 1-14, 2002.

42. Scarpulla RC: Metabolic control of mitochondrial biogenesis through the PGC-1 family regulatory network. Biochim Biophys Acta 1813: 1269-1278, 2011.

43. Mootha VK, Handschin C, Arlow D, Xie X, St Pierre J, Sihag S, Yang W, Altshuler D, Puigserver P, Patterson N, et al: Erralpha and $\mathrm{Gabpa} / \mathrm{b}$ specify PGC-1alpha-dependent oxidative phosphorylation gene expression that is altered in diabetic muscle. Proc Natl Acad Sci USA 101: 6570-6575, 2004.

44. Girnun GD: The diverse role of the PPAR $\gamma$ coactivator 1 family of transcriptional coactivators in cancer. Semin Cell Dev Biol 23: 381-388, 2012.

45. Jain A, Bakhshi S, Thakkar H, Gerards M and Singh A: Elevated mitochondrial DNA copy numbers in pediatric acute lymphoblastic leukemia: A potential biomarker for predicting inferior survival. Pediatr Blood Cancer: Nov 14, 2017 (Epub ahead of print). doi: $10.1002 / \mathrm{pbc} .26874$.

46. Wang Y, He S, Zhu X, Qiao W and Zhang J: High copy number of mitochondrial DNA predicts poor prognosis in patients with advanced stage colon cancer. Int J Biol Markers 31: e382-e388, 2016.

47. Zhang G, Qu Y, Dang S, Yang Q, Shi B and Hou P: Variable copy number of mitochondrial DNA (mtDNA) predicts worse prognosis in advanced gastric cancer patients. Diagn Pathol 8: $173,2013$.

48. Hatok J and Racay P: Bcl-2 family proteins: Master regulators of cell survival. Biomol Concepts 7: 259-270, 2016.

49. Zaltsman Y, Shachnai L, Yivgi-Ohana N, Schwarz M, Maryanovich M, Houtkooper RH, Vaz FM, De Leonardis F, Fiermonte G, Palmieri F, et al: MTCH2/MIMP is a major facilitator of tBID recruitment to mitochondria. Nat Cell Biol 12: 553-562, 2010.

50. Milane L, Trivedi M, Singh A, Talekar M and Amiji M: Mitochondrial biology, targets, and drug delivery. J Control Release 207: 40-58, 2015 